\title{
VORWORT DES HERAUSGEBERS ZUR 2. DEUTSCHEN AUFLAGE
}

In der vorliegenden zweiten deutschen Auflage sind die in der ersten deutschen Auflage im Anhang enthaltenen Ergänzungen in den Text eingefügt worden. Darüber hinaus wurden an einigen Stellen Verbesserungen vorgenommen, die freundlicherweise Herr Prof. LifschiтZ vorgeschlagen hat. Ferner haben wir alle uns bekannt gewordenen Druckfehler beseitigt.

Für die so liebenswürdige Unterstützung unserer Arbeit sei auch an dieser Stelle Herrn Prof. Lifschitz sehr herzlich gedankt. Schließlich danken wir den Herren Dr. Dautcourt (Berlin) und cand. phys. TномаS (Leipzig) für eine sehr sorgfältige Durchsicht der 1. deutschen Auflage auf Druckfehler.

Dubna, November 1963

G. Heber 